\title{
Maximizing biogas production by pretreatment and by optimizing the mixture ratio of co-digestion with organic wastes
}

\author{
Beom Lee', Jun-Gyu Park', Won-Beom Shin ${ }^{1}$, Beom-Soo Kim², Byoung-su Byun ${ }^{3}$, Hang-Bae Jun ${ }^{1^{+}}$ \\ ${ }^{1}$ Department of Environmental Engineering, Chungbuk National University, Cheongju 28644, Republic of Korea \\ ${ }^{2}$ Department of Chemical Engineering, Chungbuk National University, Cheongju 28644, Republic of Korea \\ ${ }^{3}$ Energy Policy Support Team, Korea Environment Corporation, Incheon 22689, Republic of Korea
}

\begin{abstract}
Anaerobic digestion is a popular sewage sludge (Ss) treatment method as it provides significant pollution control and energy recovery. However, the low $\mathrm{C} / \mathrm{N}$ ratio and poor biodegradability of Ss necessitate pretreatment methods that improve solubilization under anaerobic conditions in addition to anaerobic co-digestion with other substrates to improve the process efficiency. In this study, three pretreatment methods, namely microwave irradiation, ultrasonication, and heat treatment, were investigated, and the corresponding improvement in methane production was assessed. Additionally, the simplex centroid design method was utilized to determine the optimum mixture ratio of food waste $(\mathrm{Fw})$, livestock manure $(\mathrm{Lm})$, and Ss for maximum methane yield. Microwave irradiation at $700 \mathrm{~W}$ for $6 \mathrm{~min}$ yielded the highest biodegradability $(62.0 \%)$, solubilization efficiency $(59.7 \%)$, and methane production $(329 \mathrm{~mL} / \mathrm{g}$ VS). The optimum mixture ratio following pretreatment was $61.3 \%$ pretreated Ss, $28.6 \% \mathrm{Fw}$, and $10.1 \% \mathrm{Lm}$. The optimum mixture ratio without pretreatment was $33.6 \%$ un-pretreated Ss, $46.0 \% \mathrm{Fw}$, and $20.4 \% \mathrm{Lm}$. These results indicate that the choice of pretreatment method plays an important role in efficient anaerobic digestion and can be applied in operational plants to enhance methane production. Co-digestion of Ss with Fw and Lm was also beneficial.
\end{abstract}

Keywords: Anaerobic digestion, Mixture ratio, Pretreatment, Sewage sludge, Simplex centroid design

\section{Introduction}

Anaerobic digestion is one of the most attractive treatment options for treating sewage sludge (Ss) and it has been used to treat sludge produced by both municipal and industrial wastewater treatments [1]. It stabilizes the sludge into reusable biosolids and generates renewable energy (in the form of methane in biogas) [2]. Anaerobic digestion involves a series of metabolic reactions, namely hydrolysis, acidogenesis, and methanogenesis [3, 4]. Through these reactions, biodegradable materials such as food waste (Fw), livestock manure (Lm), and Ss are reduced to a mixture of methane and carbon dioxide as the principal end products [3].

Three types of sludge should be considered for sludge anaerobic digestion: primary, waste activated (or secondary) sludge, and a mixture of both. Primary sludge is already readily biodegradable whereas waste activated sludge is less biodegradable and less hydrolysable than primary sludge [2, 4]. During hydrolysis, bac- teria release extracellular enzymes that break down and solubilize organic particulate matter to use them as substrates in acidogenesis and methanogenesis [1, 3]. However microbial cells in the form of flocs and extracellular polymeric substances (EPS) in sludge are recalcitrant to hydrolysis and digestion [1, 2]. Therefore, Extensive research has been conducted on pretreatment methods to accelerate hydrolysis of organic solids to soluble organic matter [5-7]. Saha [8] pointed out the advantages of sludge solubilization prior to anaerobic digestion. One advantage is that increasing the amount of released soluble substrate enhances volatile fatty acids (VFA) generation, resulting in improved biogas yield during anaerobic digestion. The other benefit is that pretreatment decreases the viscosity of the sludge, allowing higher solids concentration in the anaerobic digester. Higher solids concentration in the feed can increase digestion times or allow for a smaller digester. Some of the available pretreatment methods as per the literature are ultrasonication, ozonation, microwave, acid, base, and heat
This is an Open Access article distributed under the terms of the Creative Commons Attribution Non-Commercial License (http://creativecommons.org/licenses/by-nc/3.0/) which permits unrestricted non-commercial use, distribution, and reproduction in any medium, provided the original work is properly cited.

Copyright (c) 2019 Korean Society of Environmental Engineers
Received October 27, 2018 Accepted January 3, 2019

${ }^{\dagger}$ Corresponding author

Email: jhbcbe@cbnu.ac.kr

Tel: +82-43-261-2470 Fax: +82-43-264-2465

ORCID: 0000-0003-1666-5982 
pretreatments [4, 9-14].

Ultrasonic waves are sound waves that propagate through a medium and dissipate a huge amount of energy while doing so. Moreover, gas and vapor bubbles are generated. They grow rapidly and collapse violently at high velocity, and this phenomenon is called cavitation $[15,16]$. It disrupts the microorganisms' cells and facilitates the availability of intracellular materials for subsequent degradation to methane and carbon dioxide [16]. Heat pretreatment has been known to increase hydrolysis rates and decrease hydraulic retention time (HRT). It has additional advantages such as sludge sanitation, reduction in sludge viscosity, and no extra energy requirements as it uses the biogas produced in excess [2]. Some of its disadvantages include an increase in soluble inert fraction, final effluent color, and ammonia inhibition, as well as poorer centrifugation [2].

Carrère et al. [2] reviewed various pretreatment methods. They noted that the optimum temperature for heat pretreament ranged from $160-180^{\circ} \mathrm{C}$ for 30 to $60 \mathrm{~m}$, resulting an increase in methane production by $14-100 \%$, mainly for waste activated sludge and a mix of primary and waste activated sludge. Borges and Chernicharo [17] observed that heat pretreatment at lower temperatures, such as $75^{\circ} \mathrm{C}$ for $7 \mathrm{~h}$, increased biogas production by $50 \%$. Carrère et al. [2] commented that the increase in methane production was related to solubilization of the chemical oxygen demand (COD) by linear correlation, but heat pretreatment at excessively high temperatures such as $170-190^{\circ} \mathrm{C}$ resulted in a decrease in sludge biodegradability [2].

Mechanical pretreatment such as ultrasonication has been widely used to pretreat the sludge prior to anaerobic digestion [18]. Low frequencies (20-40 kHz) are known to provide the most efficient treatment, resulting in biogas enhancement by $24-140 \%$ in batch systems and 10-45\% in continuous/semi-continuous systems [2].

Given the low $\mathrm{C} / \mathrm{N}$ ratio and low biodegradability of Ss for combinations of waste activated sludge, there has been increasing interest in pretreatment methods to improve solubilization under anaerobic conditions as mentioned above [2]. However, due to differences in sludge properties resulted from the region, it has been reported that the most effective pretreatment methods are different [19-21]. And Fw and Lm were compounded to improve performance of process in anaerobic digestion [22]. The co-digestion of Ss improves the performance of anaerobic digestion in terms of high biogas yield and better process stability [23]. Several combinations of organic waste with sludge prior to anaerobic digestion are operationally possible. They include brewery waste and cow dung [24], Ss and pig manure [25], agricultural resources [26], and so on. Here, according to Liu et al. [30] the effect of co-digestion is unclear, and there is no established method for estimating the appropriate input ratio. Also, as Rao and Baral [23] pointed out, typically, there is no technical basis for selecting the proportions of waste to prepare for co-digestion and improve the performance of anaerobic digestion. For this reason, determining the mixing ratio using statistical methods is being considered [27]. Statistical methods, such as the simplex centroid design method, have been used to investigate the best mixture ratio for the optimization process. Mahanty et al. [28] used the simplex centroid design method to optimize the co-digestion process for a combination of five industrial wastes. Rao and Baral [23] used it to design a mixture of Ss, cow dung, and garden waste. Wang et al. [29] applied the technique to optimize the co-digestion process for three types of manure and rice straw. Various response variables, such as cumulative methane production, volatile solids (VS) removal, and COD, were used for these investigations. However, as has been examined previously, it is necessary to accumulate data on the optimum pretreatment method due to the region-specific characteristics and the mixing ratio therefor needs to be determined statistically [36].

In this study, three methods (microwave irradiation, ultrasonic pretreatments, and heat pretreatment) were investigated for Ss (waste activated sludge with primary sludge) pretreatment to improve methane production. The Ss was pretreated. Cumulative methane production and VS removals were used as response variables and the optimum mixture ratio of co-digestion with Fw, $\mathrm{Lm}$, and pretreated Ss was determined for the maximum methane yield using the simplex centroid design. The optimum mixture ratio of co-digestion with un-pretreated Ss, Fw, and Lm for maximum methane production was also determined to compare the efficiency of the different pretreatment methods.

\section{Materials and Methods}

\subsection{Ss Pretreatments}

Collected Ss contained waste activated sludge and primary sludge and $20 \mathrm{~g} / \mathrm{L}$ TS. Three different pretreatment methods, microwave, ultrasonic, and heat pretreatments, were applied. Sieved Ss was microwave-irradiated using a household microwave oven (RE-C21VW) equipped with a rotating tray. The sieved Ss was microwaved in a $500-\mathrm{mL}$ bottle at $2,450 \mathrm{MHz}$ and $700 \mathrm{~W}$ for $6 \mathrm{~m}$. For ultrasonic pretreatment, the sieved Ss was sonicated using an ultrasonicator (Branson, Danbury, CT, USA) in 2-L reactor at $20+30 \mathrm{kHz}$ for $60 \mathrm{~min}$. During ultrasonication, the Ss was stirred, and the temperature and $\mathrm{pH}$ were monitored. For thermal hydrolysis, Ss autoclaved (CT-DAC60, Coretech) in a $500-\mathrm{mL}$ bottle at $110^{\circ} \mathrm{C}$ and under $1.0-1.3$ atm pressure for $60 \mathrm{~m}$. Then, it was cooled down for about $2 \mathrm{~h}$ until it reached room temperature. The experimental setups are illustrated in Fig. S1.

\subsection{Co-digestion Experiments}

\subsubsection{Substrates}

Fw was collected from the local municipal Fw treatment plant (Cheongju, South Korea), and livestock manure (Lm) was sourced from the local livestock treatment plant (Seoul, South Korea). In this study, Ss comprised a mixture of waste activated sludge and primary sludge prior to anaerobic digestion, and it was collected from the local municipal wastewater treatment plant (Cheongiu, South Korea). All forms of waste were ground and sieved ( $2 \mathrm{~mm}$ ) before using them in the experiments. Physicochemical properties were analyzed prior to pretreatment (Table 1). Anaerobic seed sludge (inoculum) was collected from anaerobic digesters at the Cheongju Municipal Wastewater Treatment Plant in Cheongju, South Korea. 
Table 1. Characteristics of the Three Substrates Used in this Study: Food Waste, Livestock Manure, and Sewage Sludge

\begin{tabular}{|c|c|c|c|}
\hline \multirow{2}{*}{\multicolumn{2}{|c|}{$\begin{array}{l}\text { Parameters } \\
\text { Food waste (Fw) }\end{array}$}} & Range & Average \\
\hline & & & \\
\hline \multicolumn{2}{|l|}{$\mathrm{pH}$} & $3.82-4.21$ & 4.02 \\
\hline \multicolumn{2}{|l|}{ TS (mg/L) } & $201,000-221,000$ & 211,000 \\
\hline \multicolumn{2}{|l|}{ VS (mg/L) } & $156,000-168,000$ & 126,000 \\
\hline \multicolumn{2}{|l|}{$\mathrm{TCOD}_{\mathrm{Cr}}(\mathrm{mg} / \mathrm{L})$} & $169,000-182,000$ & 175,000 \\
\hline \multicolumn{2}{|c|}{$\mathrm{SCOD}_{\mathrm{Cr}}(\mathrm{mg} / \mathrm{L})$} & $81,000-86,000$ & 83,000 \\
\hline \multirow{6}{*}{$\begin{array}{l}\text { Chemical } \\
\text { composition } \\
(\%)\end{array}$} & $\mathrm{C}$ & $51.1-54.7$ & 52.1 \\
\hline & $\mathrm{H}$ & $7.4-7.7$ & 7.6 \\
\hline & $\mathrm{O}$ & $35.4-36.9$ & 36.5 \\
\hline & $\mathrm{N}$ & $3.7-3.9$ & 3.8 \\
\hline & $S$ & - & - \\
\hline & $\mathrm{C} / \mathrm{N}$ & 13.3-13.9 & 13.7 \\
\hline \multicolumn{4}{|c|}{ Livestock manure (Lm) } \\
\hline \multicolumn{2}{|l|}{$\mathrm{pH}$} & $6.84-7.61$ & 7.37 \\
\hline \multicolumn{2}{|l|}{ TS (mg/L) } & $46,100-48,000$ & 47,050 \\
\hline \multicolumn{2}{|l|}{ VS (mg/L) } & $29,400-31,500$ & 30,450 \\
\hline \multicolumn{2}{|c|}{$\mathrm{TCOD}_{\mathrm{Cr}}(\mathrm{mg} / \mathrm{L})$} & $48,400-51,700$ & 50,050 \\
\hline \multicolumn{2}{|l|}{$\mathrm{SCOD}_{\mathrm{Cr}}(\mathrm{mg} / \mathrm{L})$} & $38,100-39,200$ & 38,650 \\
\hline \multirow{6}{*}{$\begin{array}{l}\text { Chemical } \\
\text { composition } \\
(\%)\end{array}$} & $\mathrm{C}$ & $47.4-48.9$ & 48.4 \\
\hline & $\mathrm{H}$ & $5.7-6.4$ & 6.0 \\
\hline & $\mathrm{O}$ & 18.7-19.6 & 19.4 \\
\hline & $\mathrm{N}$ & $3.2-3.5$ & 3.3 \\
\hline & S & - & - \\
\hline & $\mathrm{C} / \mathrm{N}$ & $14.4-14.9$ & 14.7 \\
\hline \multicolumn{4}{|l|}{ Sewage sludge } \\
\hline \multicolumn{2}{|l|}{$\mathrm{pH}$} & $6.94-7.32$ & 7.13 \\
\hline \multicolumn{2}{|l|}{ TS (mg/L) } & $25,945-28,447$ & 27,196 \\
\hline \multicolumn{2}{|l|}{ VS (mg/L) } & $15,048-16,352$ & 15,700 \\
\hline \multicolumn{2}{|c|}{$\mathrm{TCOD}_{\mathrm{Cr}}(\mathrm{mg} / \mathrm{L})$} & $26,700-31,700$ & 29,200 \\
\hline \multicolumn{2}{|l|}{$\mathrm{SCOD}_{\mathrm{Cr}}(\mathrm{mg} / \mathrm{L})$} & $981-1,041$ & 1,011 \\
\hline \multirow{6}{*}{$\begin{array}{l}\text { Chemical } \\
\text { composition } \\
(\%)\end{array}$} & $\mathrm{C}$ & $54.2-58.8$ & 57.1 \\
\hline & $\mathrm{H}$ & 7.1-7.7 & 7.3 \\
\hline & $\mathrm{O}$ & $30.1-30.9$ & 30.4 \\
\hline & $\mathrm{N}$ & $5.0-5.4$ & 5.2 \\
\hline & $\mathrm{S}$ & $1.6-1.7$ & 1.7 \\
\hline & $\mathrm{C} / \mathrm{N}$ & $10.7-11.2$ & 11.0 \\
\hline
\end{tabular}

\subsubsection{Biochemical methane potential (BMP)}

BMP test was conducted to determine the cumulative methane yield at $35^{\circ} \mathrm{C}$. The test was performed in duplicate according to Owen et al. [31] in 500-mL serum bottles consisting of 30 $\mathrm{mL}$ of anaerobic seed sludge and $300 \mathrm{~mL}$ of nutrient stock solution (prepared using the following (in g/L): $\mathrm{KH}_{2} \mathrm{PO}_{4}-0.27, \mathrm{~K}_{2} \mathrm{HPO}_{4}-0.35$, $\mathrm{NH}_{4} \mathrm{Cl}-0.53, \mathrm{CaCl}_{2} \cdot 2 \mathrm{H}_{2} \mathrm{O}-0.075, \mathrm{MgCl} \cdot 6 \mathrm{H}_{2} \mathrm{O}-0.1, \mathrm{FeCl}_{2} \cdot 4 \mathrm{H}_{2} \mathrm{O}-0.2$, $\mathrm{MnCl}_{2}-0.0005, \mathrm{H}_{3} \mathrm{BO}_{3}-0.00005, \mathrm{ZnCl}_{3}-0.00005, \mathrm{CuCl}_{2}-0.00003$, $\mathrm{NaNO}_{4}-0.00001, \mathrm{CoCl}_{2} \cdot 6 \mathrm{H}_{2} \mathrm{O}-0.0005, \mathrm{NiCl}_{2} \cdot 6 \mathrm{H}_{2} \mathrm{O}-0.00005$, and
$\left.\mathrm{Na}_{2} \mathrm{SeO}_{3}-0.00005\right)$. It was purged with nitrogen gas to develop an anaerobic environment. Three substrates (Fw, Lm, and Ss) were dispensed into the serum bottles based on the experimental mixture design to arrive at a final concentration of $1 \mathrm{~g} / \mathrm{L} \mathrm{VS}$ equivalent. The $\mathrm{pH}$ was adjusted to 7 using $1 \mathrm{~N} \mathrm{NaOH}$ and 1 $\mathrm{N} \mathrm{HCl}$, and $1.2 \mathrm{~g} / \mathrm{L} \mathrm{NaHCO}_{3}$ was added to prevent the $\mathrm{pH}$ from decreasing due to volatile (VFA) production. After purging with nitrogen gas, the serum bottle was incubated at $35^{\circ} \mathrm{C}$. Biogas production was measured at regular intervals.

\subsubsection{Analytical methods}

TCOD $_{\mathrm{Cr}}$ was measured in the supernatant organic fraction after solid/liquid separation using a centrifuge (MF-80, Hanil, Korea, 3,000 rpm, $5 \mathrm{~m}$ ), while other dissolved water quality parameters $\left(\mathrm{SCOD}_{\mathrm{Cr}}\right)$ were analyzed in the supernatant organic fraction after filtration through a $1.2 \mu \mathrm{m} \mathrm{GF/C} \mathrm{glass} \mathrm{fiber} \mathrm{filter} \mathrm{(GF/CTM,}$ Whatman, England). Gas chromatography (GOW-MAC Series 580, GOW-MAC Instrument Co., Bethlehem, PA, USA) with a built-in thermal conductivity detector was used to analyze the composition of the generated biogas. The carrier gas used was ultra-pure helium at a flow velocity of $15 \mathrm{~mL} / \mathrm{m}$. The temperatures of the column, injector, and detector were fixed at 50,80 , and $90^{\circ} \mathrm{C}$, respectively. Values for $\mathrm{pH}$ were measured using a $\mathrm{pH}$ meter (Orion $420 \mathrm{~A}^{+}$, Thermo Fisher Scientific, Waltham, MA, USA). Other assays (TS and VS) were conducted using standard methods [32]. The samples were dried at $105 \pm 5^{\circ} \mathrm{C}$, ground, and subjected to elemental (C, H, O, N) analysis using an elemental analyzer (LECO Co., 628 Series, USA). Theoretical methane production was calculated from the elemental composition, using Eq. (1) [31].

$$
\begin{gathered}
C_{a} H_{b} O_{c} N_{d}+\left(\frac{4 a-b-2 c+3 d}{4}\right) H_{2} O \rightarrow \\
\left(\frac{4 a+b-2 c-3 d}{8}\right) C H_{4}+\left(\frac{4 a-b+2 c+3 d}{8}\right) C_{2}+d \mathrm{NH}_{3}
\end{gathered}
$$

Theoretical methane production $\left(\mathrm{STP} \mathrm{m}^{3} / \mathrm{kg} \mathrm{VS}_{\text {added }}\right)=$

$$
\frac{22.4\left(\frac{4 a+b-2 c-3 d}{8}\right)}{12 a+b+16 c+14 d}
$$

where STP is the standard temperature and pressure.

Biodegradability was calculated using Buswell's equation [33]:

$$
\begin{gathered}
\text { Biodegradability }(\%)= \\
\left(\frac{\text { Cumulative methane yield }}{\text { Theoretical methane yield }}\right) \times 100 \\
\text { Solubilization efficiency }(\%)= \\
\frac{S C O D_{\text {eff }}-S C O D_{\text {inf }}}{T C O D_{\text {inf }}-S C O D_{\text {inf }}} \times 100
\end{gathered}
$$

where $\mathrm{SCOD}_{\text {eff }}$ is the soluble COD of the effluent, SCOD $\mathrm{Sin}_{\text {is }}$ the soluble COD of the influent, and TCOD $_{\text {inf }}$ is the total COD of the influent. 


\subsubsection{Mixture design}

The simplex centroid design method has been used to study the effects of mixture components on the response variable [24]. In this study, the simplex centroid design method was used to determine the optimum mixture ratio of three substrates, namely $\mathrm{Fw}$, Ss, and Lm, in anaerobic co-digestion for maximum methane production [24]. The special cubic equation was used [24].

$$
\begin{gathered}
Y=\sum_{i=1}^{q} \beta_{i} x_{i}+\sum_{i<j}^{q} \beta_{i j} x_{i} x_{j}+ \\
\sum_{i<j<k}^{q} \beta_{i j k} x_{i} x_{j} x_{k}
\end{gathered}
$$

where $Y$ represented the methane yield or VS removal variable of the process. $\beta_{i}$ was the expected response to the pure combination (regression coefficient) $x_{i}=1$ and $x_{j}=0$ when $j \neq i$.

MINITAB® Release 14 (Minitab Inc., US) software was used to determine the optimum proportions for each substrate combination. All proportions of three substrates in each mixture were summed to $100 \%$ and a total of 10 experimental runs were conducted. It was assumed that the measured response depended only on the proportions of the substrates present in the mixture. When all the environmental factors were held constant, the response measures as cumulative methane production and VS removal were the functions of only the proportions of feed substrates used. ANOVA was used to test the fitness of the model, and response surface methods were used to determine the optimum mixture ratio for maximum methane production.

Then, methane production from the best mixture ratio of un-pretreated Ss, Fw, and Lm was compared with that from the best mixture ratio of pretreated (microwave-irradiated) Ss, Fw, and Lm.

\section{Results and Discussion}

\subsection{Pretreatments}

Microwave-irradiated Ss showed the highest solubilization efficiency, followed by ultrasonicated Ss (59.7 and 59.2\%, respectively; Table 2). It is known that acoustic cavitation during ultrasonication occurs more readily in the range of $20-40 \mathrm{kHz}$ [15], and such low frequencies have been known to be the most effective for sludge floc disintegration [2]. Based on this understanding, ultrasonication at $20+30 \mathrm{kHz}$ was selected. Under these conditions, the results (Table 2) showed that the method was efficient at solubilizing the sludge. The thermally treated Ss showed a solubilization efficiency of $5.2 \%$ only (Table 2). Park [34] observed that SCOD concentration increased by 12 times with microwave-irradiation, and this result was similar to the result of this study, that is, an increase by 16 times. The BMP test results for cumulative methane production are shown in Table S1. The highest biodegradability (as a measure by methane production) and highest methane production was achieved by microwave irradiation (62.0\% and $329 \mathrm{~mL} \mathrm{CH}_{4} / \mathrm{g}$ VS, respectively) (Fig. 1). The second highest biodegradability was achieved by ultrasonication (60.8\%), and the lowest biodegradability was observed with heat treatment $(32.0 \%)$. Low frequencies $(20-40 \mathrm{kHz}$ ) have been recognized as the most efficient [2]. Microwave irradiation and ultrasonic treatment have been known to cause sludge floc disintegration and cell lysis [16, 34]. The results showed that these two treatment methods resulted in high sludge solubilization and biodegradability (Table 2 and Fig. 1). The extent of hydrolysis can be indicated by solubilization efficiency as well as the SCOD/TCOD ratio, as shown in Table 2. The SCOD/TCOD ratios increased from 0.025 to $0.627,0.608$, and 0.077 for the microwave irradiation, ultrasonic wave, and heat treatments, respectively. Eskicioglu et al. [11] also studied microwave irradiation $(1,250$ $\left.\mathrm{W}, 2,450 \mathrm{MHz}, 96^{\circ} \mathrm{C}\right)$ and heat pretreatment $\left(96^{\circ} \mathrm{C}\right)$ and observed that the SCOD/TCOD ratios increased from 0.06 (before treatment) to 0.15 and 0.27 for microwave and heat pretreatment, respectively. Heat pretreatment provided better hydrolysis performance compared to microwave treatment. Guo et al. [12] found that the SCOD/TCOD ratio increased from 0.10 to 0.18 for heat pretreatment/sterilization $\left(121^{\circ} \mathrm{C}\right.$ for $\left.30 \mathrm{~m}\right)$, from 0.01 to 0.09 for microwave irradiation ( $560 \mathrm{~W}$ for $2 \mathrm{~m}$ ), and from 0.01 to 0.13 for ultrasonic treatment $(5 \mathrm{~m})$. In their study, ultrasonic treatment resulted in a slightly the better performance than microwave irradiation.

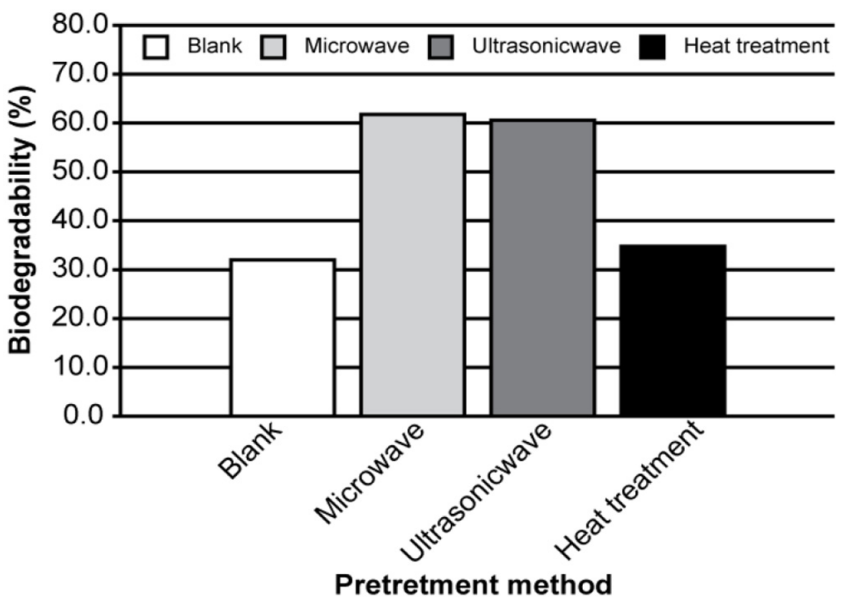

Fig. 1. Biodegradability for each pretreatment method.

\begin{tabular}{|c|c|c|c|c|c|c|c|}
\hline \multirow{2}{*}{ Pretreatment methods } & \multirow{2}{*}{ TS (mg/L) } & \multirow{2}{*}{ TCOD $(\mathrm{mg} / \mathrm{L})$} & \multicolumn{2}{|c|}{ SCOD (mg/L) } & \multicolumn{2}{|c|}{ SCOD/TCOD ratios } & \multirow{2}{*}{$\begin{array}{l}\text { Solubilization } \\
\text { efficiency (\%) }\end{array}$} \\
\hline & & & Before & After & Before $^{\#}$ & After & \\
\hline Microwave (700 W, 6 min) & 20,000 & 29,200 & 730 & 13,790 & 0.025 & 0.627 & 59.7 \\
\hline Ultrasonic wave $(20+30 \mathrm{kHz}, 60 \mathrm{~min})$ & 20,000 & 29,200 & 730 & 13,386 & 0.025 & 0.608 & 59.5 \\
\hline Heat treatment $\left(110^{\circ} \mathrm{C}, 60 \mathrm{~m}\right)$ & 20,000 & 29,200 & 730 & 1,686 & 0.025 & 0.077 & 5.2 \\
\hline
\end{tabular}

Table 2. Solubilization Efficiency of Pretreatment Methods Employed in this Study

${ }^{\#}$ SCOD ${ }_{\text {before }} /$ TCOD $_{\text {before }}=730 / 29,200$ 
Overall, the findings indicated the strong effect of microwave irradiation and ultrasonic waves on sludge solubilization and methane production. Also, as summarized in the Table S2, it can be seen that the highest efficiency pretreatment method and methane emission amount are different for each document. These results are considered to be caused by differences in properties of sludge resulted from the region.

In this study, microwave irradiation appeared to be the best pretreatment, and thus, the subsequent experiments for the optimum co-digestion mixture ratio with $\mathrm{Ss}$, Fw, and Lm were conducted using microwave pretreatment.

\subsection{Determination of Mixture Ratio}

Using the simplex centroid design, the mixture ratio of Ss, Fw, and Lm was determined. The mixture ratio of the three samples was based on $100 \%$ volume. It generated 10 waste substrate runs, as shown in Table S3.

\subsection{BMP Test Results According to Mixture Ratio}

Using microwave-pretreated Ss and un-pretreated Ss, the BMP test was conducted for the 10 mixture ratios derived from the simple centroid design. Both before and after pretreatment, the cumulative methane production of Run 3, in which 100\% Fw was subjected to anaerobic digestion, was found to be the highest

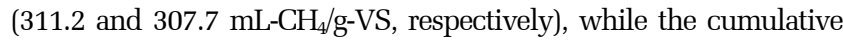
methane production of Run 4, in which only Lm was subjected to anaerobic digestion, exhibited the lowest values (124.7 and

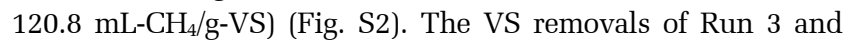
8 , in which $100 \%$ and $66.7 \% \mathrm{Fw}$ were mixed, were found to be high, both before and after pretreatment (Table 3). For R1 and R10, while $50 \% \mathrm{Fw}$ was mixed in the same mixture ratio, VS removals were measured to be $42.1 \%$ and $64.1 \%$, respectively, before pretreatment, and they exhibited different values of $41.4 \%$ and $63.4 \%$ after pretreatment. This appears to be because the VS removal of Lm was lower than that of Ss. In addition, in each condition that included Ss, the cumulative methane production and VS removal exhibited higher efficiency than those for the co-digestion of un-pretreated Ss, because biodegradability increased due to the pretreatment of Ss. The efficiency of the cumulative methane production, VS removal, and biodegradability depended on the mixture ratio of Fw. In particular, the cumulative methane production of R8, in which $66.7 \% \mathrm{Fw}$ was mixed was found to be the highest, except for the anaerobic digestion of Fw alone. As a result, it was found that Fw exhibits higher VS removal than Ss and Lm, and thus, its biodegradability is also high when subjected to anaerobic digestion. Callaghan et al. reported that methane production increases as the ratio of organic wastes with high carbon contents increases in the mesophilic digestion process [35]. Similarly, Yu et al. [13] also reported that methane production increases as the ratio of organic wastes with high biodegradability increases, because methane production increased from $282 \mathrm{~mL}$ to $311 \mathrm{~mL}$ when the mixture ratio of Fw increased from $32 \%$ to $48 \%$.

\subsection{Rare Analysis by Mixture Ratio}

The coefficient of determination (R-sq) was calculated to numerically express the accuracy of cumulative methane production and VS removal depending on the mixture ratio. As a result, the R-sq values of cumulative methane production were $97.4 \%$ and $97.0 \%$, respectively, before and after pretreatment (Table 4), and those of VS removal were $90.4 \%$ and $95.2 \%$, respectively (Table 5). In addition, the T- and P-values were analyzed to assess the significance of the coefficients. For cumulative methane production, all of the first, second $(\mathrm{Fw} \times \mathrm{Lm})$, and third terms exhibited positive values except Ss $\times$ Fw and Ss $\times$ Lm of the second term. For VS removal, all of the first, second ( $\mathrm{Ss} \times \mathrm{Fw}$ ), and third terms exhibited positive values except $\mathrm{Ss} \times \mathrm{Lm}$ and $\mathrm{Fw} \times \mathrm{Lm}$ of the second term. Mixture equations before pretreatment, which exclude the insignificant coefficients of sludge, are as shown in Eq. (6) and (7), and those after pretreatment are as shown in Eq. (8) and (9).

$$
\begin{aligned}
& \text { Cumulative methane yield }=144.8 \mathrm{X}_{1}+308.9 \mathrm{X}_{2}+ \\
& 50.4 \mathrm{X}_{3}+104.3 \mathrm{X}_{2} \mathrm{X}_{3}+2,360.5 \mathrm{X}_{1} \mathrm{X}_{2} \mathrm{X}_{3} \\
& \text { VS removal }=35.05 \mathrm{X}_{1}+65.8 \mathrm{X}_{2}+ \\
& 41.1 \mathrm{X}_{3}+65.7 \mathrm{X}_{1} \mathrm{X}_{2}+72.4 \mathrm{X}_{1} \mathrm{X}_{2} \mathrm{X}_{3}
\end{aligned}
$$

Cumulative methane yield $=187.6 \mathrm{X}_{1}+305.4 \mathrm{X}_{2}+$

\begin{tabular}{|c|c|c|c|c|c|c|}
\hline \multirow[b]{2}{*}{ Run } & \multicolumn{3}{|c|}{ Before pretreatment } & \multicolumn{3}{|c|}{ After pretreatment } \\
\hline & $\begin{array}{l}\text { Cumulative methane } \\
\text { production }(\mathrm{mL} / \mathrm{g} \text { VS) }\end{array}$ & $\begin{array}{c}\text { VS removal } \\
(\%)\end{array}$ & $\begin{array}{c}\text { Biodegradability } \\
\text { (\%) }\end{array}$ & $\begin{array}{l}\text { Cumulative methane } \\
\text { production }(\mathrm{mL} / \mathrm{g} \text { VS) }\end{array}$ & $\begin{array}{c}\text { VS removal } \\
(\%)\end{array}$ & $\begin{array}{c}\text { Biodegradability } \\
\text { (\%) }\end{array}$ \\
\hline 1 & 204.4 & 42.1 & 67.8 & 209.7 & 41.4 & 68.1 \\
\hline 2 & 194.8 & 54.8 & 48.4 & 239.4 & 57.4 & 62.4 \\
\hline 3 & 311.2 & 65.7 & 79.6 & 307.7 & 64.1 & 80.3 \\
\hline 4 & 124.7 & 43.5 & 58.4 & 120.8 & 44.8 & 56.1 \\
\hline 5 & 138.4 & 32.4 & 41.4 & 180.2 & 47.6 & 61.2 \\
\hline 6 & 208.7 & 48.2 & 58.2 & 241.0 & 54.8 & 65.8 \\
\hline 7 & 130.4 & 33.6 & 52.4 & 160.7 & 38.9 & 58.7 \\
\hline 8 & 278.6 & 59.4 & 70.1 & 294.1 & 63.7 & 73.4 \\
\hline 9 & 155.2 & 32.8 & 55.4 & 174.0 & 40.7 & 61.5 \\
\hline 10 & 200.4 & 64.1 & 65.1 & 223.0 & 63.4 & 71.1 \\
\hline
\end{tabular}
$51.7 \mathrm{X}_{3}+126.6 \mathrm{X}_{2} \mathrm{X}_{3}+2,605.6 \mathrm{X}_{1} \mathrm{X}_{2} \mathrm{X}_{3}$

Table 3. Response Values before and after Ss Pretreatment 


$$
\begin{gathered}
\text { VS removal }=48.5 \mathrm{X}_{1}+65.0 \mathrm{X}_{2}+43.4 \mathrm{X}_{3}+ \\
33.9 \mathrm{X}_{1} \mathrm{X}_{2}+254.4 \mathrm{X}_{1} \mathrm{X}_{2} \mathrm{X}_{3}
\end{gathered}
$$

Where,

$\mathrm{X}_{1}$ : Mixture ratio of $\mathrm{Ss}(\%)$

$\mathrm{X}_{2}$ : Mixture ratio of $\mathrm{Fw}(\%)$

$\mathrm{X}_{3}$ : Mixture ratio of $\mathrm{Lm} \mathrm{( \% )}$

As a result of regression analysis, it was found that cumulative methane production and VS removal had a synergy effect when Ss, Fw, and Lm were subjected to co-digestion simultaneously.
A comparison with the results of the BMP test indicates that higher efficiency can be derived by increasing the mixture ratio of $\mathrm{Fw}$ with a high organic content. This result is in agreement with the results of Callaghan et al., who reported that the mixture ratio of food waste must be high to achieve a synergy effect during co-digestion [35]. Next, after Ss, Fw, and Lm were fixed at three points in Fig. 2 and the mixture ratio condition of the simplex centroid design was distributed. A contour-shaped surface graph was used to show the effect of each mixture ratio on the result. Higher ratios of food waste in the mixture were found to favor

\begin{tabular}{|c|c|c|c|c|c|c|c|c|}
\hline \multirow{2}{*}{ Term } & \multicolumn{4}{|c|}{ Before sewage sludge pretreatment } & \multicolumn{4}{|c|}{ After sewage sludge pretreatment } \\
\hline & Coef & SE Coef & $\mathbf{T}$ & $\mathbf{P}$ & Coef & SE Coef & $\mathbf{T}$ & $\mathbf{P}$ \\
\hline Ss & 144.8 & 23.75 & - & - & 187.6 & 24.7 & - & - \\
\hline Fw & 308.9 & 23.75 & - & - & 305.4 & 24.7 & - & - \\
\hline $\mathrm{Lm}$ & 50.4 & 23.75 & - & - & 51.7 & 24.7 & - & - \\
\hline Ss $\times \mathrm{Fw}$ & -89.3 & 119.53 & -0.75 & 0.509 & -73.4 & 124.1 & -0.59 & 0.596 \\
\hline Ss $\times \mathrm{Lm}$ & -228.6 & 119.53 & -1.91 & 0.152 & -172.2 & 124.1 & -1.39 & 0.260 \\
\hline $\mathrm{Fw} \times \mathrm{Lm}$ & 104.3 & 119.53 & 0.87 & 0.447 & 126.6 & 124.1 & 1.02 & 0.383 \\
\hline \multirow[t]{2}{*}{ Ss $\times \mathrm{Fw} \times \mathrm{Lm}$} & $2,360.5$ & 788.01 & 3.00 & 0.058 & $2,605.6$ & 818.4 & 3.18 & 0.050 \\
\hline & \multicolumn{4}{|c|}{$\mathrm{S}=24.56$} & \multicolumn{4}{|c|}{$S=25.51$} \\
\hline
\end{tabular}

Table 4. Estimated Regression Coefficients $\left(R^{2}\right)$ for Cumulative Methane Production for Un-pretreated and Pretreated Ss

\begin{tabular}{|c|c|c|c|c|c|c|c|c|}
\hline \multirow{2}{*}{ Term } & \multicolumn{4}{|c|}{ Before sewage sludge pretreatment } & \multicolumn{4}{|c|}{ After sewage sludge pretreatment } \\
\hline & Coef & SE Coef & $\mathbf{T}$ & $\mathbf{P}$ & Coef & SE Coef & $\mathbf{T}$ & $\mathbf{P}$ \\
\hline Ss & 35.05 & 6.64 & - & - & 48.5 & 3.71 & - & - \\
\hline Fw & 65.81 & 6.64 & - & - & 65.0 & 3.71 & - & - \\
\hline $\mathrm{Lm}$ & 41.14 & 6.64 & - & - & 43.4 & 3.71 & - & - \\
\hline Ss $\times \mathrm{Fw}$ & 65.71 & 33.43 & 1.97 & 0.144 & 33.9 & 18.68 & 1.82 & 0.167 \\
\hline Ss $\times \mathrm{Lm}$ & -16.82 & 33.43 & -0.50 & 0.650 & -30.1 & 18.68 & -1.61 & 0.206 \\
\hline $\mathrm{Fw} \times \mathrm{Lm}$ & -54.51 & 33.43 & -1.63 & 0.201 & -53.1 & 18.68 & -2.84 & 0.066 \\
\hline \multirow[t]{2}{*}{ Ss $\times \mathrm{Fw} \times \mathrm{Lm}$} & 72.42 & 220.39 & 0.33 & 0.764 & 254.4 & 123.15 & 2.07 & 0.131 \\
\hline & \multicolumn{4}{|c|}{$\mathrm{S}=6.87$} & \multicolumn{4}{|c|}{$\mathrm{S}=3.84$} \\
\hline
\end{tabular}

Table 5. Estimated Regression Coefficients $\left(R^{2}\right)$ for VS Removal from Un-pretreated and Pretreated Ss
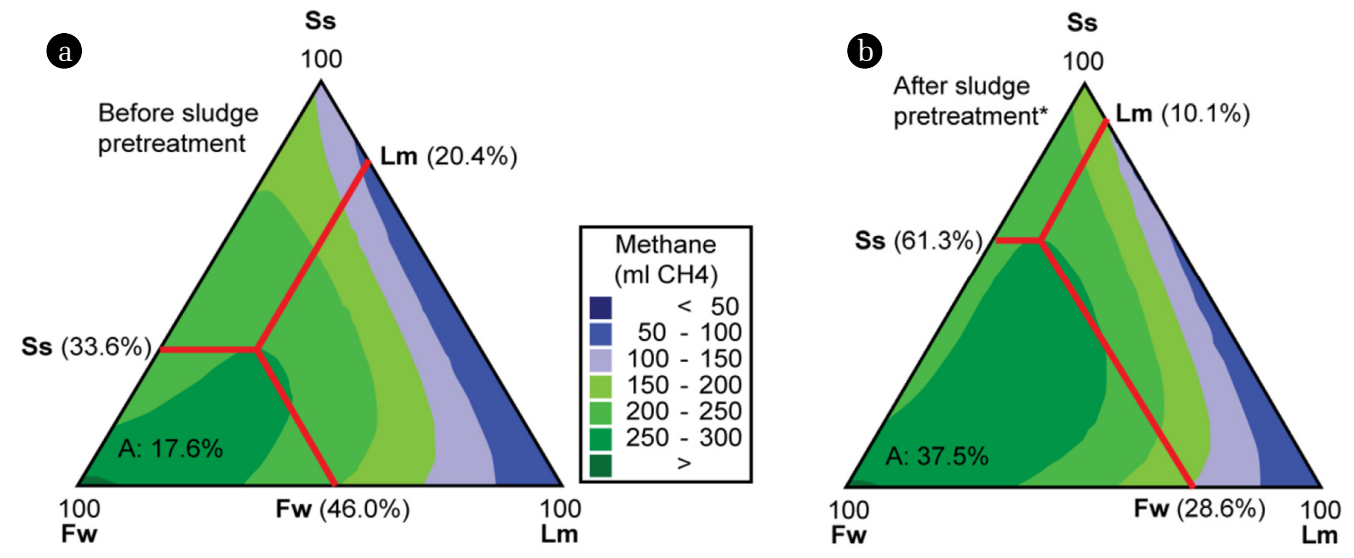

Fig. 2. Methane production by co-digestion: (a) before and (b) after pretreatment. 
the maximization of methane production during the co-digestion of Ss, Fw, and Lm, regardless of sludge pretreatment. In addition, as can be seen from Fig. 2(a), in which un-pretreated Ss was mixed, and Fig. 2(b), in which pretreated Ss was mixed, cumulative methane production higher than $300 \mathrm{~mL}-\mathrm{CH}_{4} / \mathrm{g}$-VS occurred when $\mathrm{Fw}$ alone was digested. This appears to be because of the high organic content and high biodegradability of Fw. Here, low methane production occurs when Ss or Lm alone is digested, but methane production of $250-300 \mathrm{~mL}-\mathrm{CH}_{4} / \mathrm{g}$-VS can be induced, depending on the mixture ratio of each substrate. Various mixture ratios can yield methane production in the range of 250-300 $\mathrm{mL}-\mathrm{CH}_{4} / \mathrm{g}-\mathrm{VS}$, but the optimum mixture ratio was found to be $33.6 \% \mathrm{Ss}, 46.0 \% \mathrm{Fw}$, and $20.4 \% \mathrm{Lm}$ before pretreatment. The optimum ratio after pretreatment was found to be $61.3 \% \mathrm{Ss}, 28.6 \%$ $\mathrm{Fw}$, and $10.1 \% \mathrm{Lm}$, respectively.

\subsection{Analysis of Co-Digestion Before and After Pretreatment}

Table 6 shows the co-digestion results of Ss before and after pretreatment. Through the results described in the previous section, it was found that co-digestion with organic wastes is more favorable to cumulative methane production than the $100 \%$ anaerobic digestion of Ss. However, it is difficult to process the total amount of Ss through the co-digestion of un-pretreated Ss, because Ss accounts for $61.7 \%$ of the organic waste that is subjected to anaerobic digestion in South Korea. Only 33.6\% Ss can be used in the mixture during the co-digestion of un-pretreated Ss, which is $54 \%$ of the total amount of Ss generated in South Korea. Therefore, microwave pretreatment was performed followed by co-digestion to increase the solubilization of Ss. As a result, the mixture ratio of Ss was $61.3 \%$ (1.8 times the mixture ratio before pretreatment), which was similar to the total amount of Ss generated.

In addition, as can be seen from Fig. 2, for co-digestion after pretreatment (37.5\%), the mixing range capable of obtaining the cumulative methane production of $250-300 \mathrm{~mL}^{-\mathrm{CH}_{4}} / \mathrm{g}-\mathrm{VS}$ was approximately 2.1 times that for co-digestion before pretreatment (17.6\%). This favors flexibility in the operation of co-digestion for the mixture ratios of Ss, Fw, and Lm, which are produced in varying amounts, depending on the situation. It is expected that energy recovery and economic efficiency will increase and secondary environmental pollution will be reduce using this approach.

Table 6. Analysis of Co-Digestion before and after Ss Pretreatment

\begin{tabular}{cccc}
\hline & & $\begin{array}{c}\text { Before Ss } \\
\text { pretreatment }\end{array}$ & $\begin{array}{c}\text { After Ss } \\
\text { pretreatment }\end{array}$ \\
\hline $\begin{array}{c}\text { Optimum } \\
\text { mixture } \\
\text { ratio }\end{array}$ & Ss & $33.6 \%$ & $61.3 \%$ \\
$250-300 \mathrm{~mL}^{-\mathrm{CH}_{4}}$ area & $46.0 \%$ & $28.6 \%$ \\
\hline
\end{tabular}

\section{Conclusions}

Ss, which is a mixture of waste activated sludge and primary sludge, requires pretreatment in order to enhance anaerobic digestion performance. The highest biodegradability (62.0\%), solubili- zation efficiency (59.7\%), and methane production (329 $\mathrm{mL} \mathrm{CH}_{4} / \mathrm{g}$ VS) was achieved by microwave irradiation. Thus, microwave irradiation (700 W for $6 \mathrm{~m}$ ) was used in the subsequent co-digestion study as the sludge pretreatment method. Co-digestion with pretreated Ss produced higher cumulative methane production than co-digestion with un-pretreated Ss.

Analysis of the cumulative methane yield measured according to the mixture ratio of pretreated Ss using the simplex centroid design method, the optimum mixture ratio was found to be $61.3 \%$ Ss, $28.8 \% \mathrm{Fw}$, and $10.1 \% \mathrm{Lm}$. The optimum mixture ratio of Ss after pretreatment (61.3\%) was 1.8 times the ratio before pretreatment $(33.6 \%)$, and the mixing range after pretreatment $(37.5 \%)$ was also 2.1 times the mixing range before pretreatment (17.6\%). This allows for flexibility in the mixture ratios of Ss, Fw, and Lm, which are produced in varying amounts, depending on the situation. It is expected that energy recovery and economic efficiency will increase and secondary environmental pollution will reduce using this approach.

\section{Acknowledgments}

This research was supported by Basic Science Research Program through the National Research Foundation of Korea (NRF) funded by the Ministry of Education (NRF-2018R1D1A3B07048118).

\section{References}

1. Ahn JH, Shin SG, Hwang S. Effect of microwave irradiation on the disintegration and acidogenesis of municipal secondary sludge. Chem. Eng. J. 2009;153:145-150

2. Carrère H, Dumas C, Battimelli A, et al. Pretreatment methods to improve sludge anaerobic degradability: A review. J. Hazard. Mater. 2010;183:1-15

3. Siegart I, Banks C. The effect of volatile fatty acid additions on the anaerobic digestion of cellulose and glucose in batch reactors. Process Biochem. 2005;40:3412-3418.

4. Bourgrier C, Albasi C, Delgenès JP, Carrère H. Effect of ultrasonic, thermal and ozone pre-treatments on waste activated sludge solubilisation and anaerobic biodegradability. Chem. Eng. Proc. 2006;45:711-718.

5. Jain S, Jain S, Wolf IT, Lee J, Tong YW. A comprehensive review on operating parameters and different pretreatment methodologies for anaerobic digestion of municipal solid waste. Renew. Sust. Energ. Rev. 2015;52:142-154.

6. Zhen G, Lu X, Kato H, Zhao Y, Li YY. Overview of pretreatment strategies for enhancing sewage sludge disintegration and subsequent anaerobic digestion: Current advances, full-scale application and future perspectives. Renew. Sust. Energ. Rev. 2017;69:559-577

7. Esposito G, Frunzo L, Giordano A, Liotta F, Panico A, Pirozzi F. Anaerobic co-digestion of organic wastes. Rev. Environ. Sci. Bio/Technol. 2012;11:325-341.

8. Saha M, Eskicioglu C, Marin J. Microwave, ultrasonic and chemo-mechanical pretreatments for enhancing methane potential of pulp mill wastewater treatment sludge. Bioresour. 
Technol. 2011;102:7815-7826.

9. Kim J, Park C, Kim T-H, et al. Effects of various pretreatments for enhanced anaerobic digestion with waste activated sludge. J. Biosci. Bioeng. 2003;95:271-275.

10. Eskicioglu C, Kennedy KJ, Droste RL. Characterization of soluble organic matter of waste activated sludge before and after thermal pretreament. Water Res. 2006;40:3725-3736.

11. Eskicioglu C, Terzian N, Kennedy KJ, Droste RL, Hamoda M. A thermal microwave effects for enhancing digestibility of waste activated sludge. Water Res. 2007;41:2457-2466.

12. Guo L, Li X-M, Bo X, et al. Impacts of sterilization, microwave and ultrasonication pretreatment on hydrogen producing using waste sludge. Bioresour. Technol. 2008;99:3651-3658.

13. Yu GH, He PJ, Shao LM, Zhu YS. Extracellular proteins, polysaccharides and enzymes impact on sludge aerobic digestion after ultrasonic pretreatment. Water Res. 2008;42:1925-1934.

14. Wang J, Wan W. Comparison of different pretreatment methods for enriching hydrogen-producing bacteria from digested sludge. Int. J. Hydrog. Energ. 2008;33:2934-2941.

15. Chu CP, Chang BV, Liao GS, Jean DS, Lee DJ. Observations on changes in ultrasonically treated waste-activated sludge. Water Res. 2001;35:1038-1046.

16. Pilli S, Bhunia P, Yan S, LeBlanc RJ, Tyagi RD, Surampalli RY. Ultrasonic pretreatment of sludge: A review. Ultrason. Sonochem. 2011;18:1-18.

17. Borges ESM, Chernicharo CAL. Effect of thermal treatment of anaerobic sludge on the bioavailability and biodegradability characteristics of the organic fraction. Braz. J. Chem. Eng. 2009;26:469-480.

18. Haider MR, Yousaf S, Malik RN, Visvanathan C. Effect of mixing ratio of food waste and rice husk co-digestion and substrate to inoculum ratio on biogas production. Bioresour. Technol. 2015;190:451-457.

19. Marin J, Kennedy KJ, Eskicioglu C. Effect of microwave irradiation on anaerobic degradability of model kitchen waste. Waste Manage. 2010;30:1772-1779.

20. Shahriari H, Warith M, Hamoda M, Kennedy K. Evaluation of single vs. staged mesophilic anaerobic digestion of kitchen waste with and without microwave pretreatment. J. Environ. Manage. 2013;125:74-84.

21. Zhang J, Lv C, Tong J, et al. Optimization and microbial community analysis of anaerobic co-digestion of food waste and sewage sludge based on microwave pretreatment. Bioresour. Technol. 2016;200;253-261.

22. Zhang W, Zhang L, Li A. Anaerobic co-digestion of food waste with MSW incineration plant fresh leachate: Process perform- ance and synergistic effects. Chem. Eng. J. 2015;259:795-805. 23. Rao PV, Baral SS. Experimental design of mixture for the anaerobic co-digestion of sewage sludge. Chem. Eng. J. 2011;172:977-986.

24. Tewelde S, Eyalarasan K, Radhamani R, Kathikeyan K. Biogas production from co-digestion of brewery waste and cattle dung. Int. J. Latest Trends Agr. Food Sci. 2012;2:90-93.

25. Murto M, Björnsson L, Mattiasson B. Impact of food industrial waste on anaerobic co-digestion of sewage sludge and pig manure. J. Environ. Manage. 2004;70:101-107.

26. Ward AJ, Hobbs PJ, Holliman PJ, Jones DL. Optimisation of the anaerobic digestion of agricultural resources. Bioresour. Technol. 2008;99:7928-7940.

27. Braguglia CM, Gallipoli A, Gianico A, Pagliaccia P. Anaerobic bioconversion of food waste into energy: A critical review. Bioresour. Technol. 2018;248(Pt A):37-56.

28. Mahanty B, Zafar M, Han MJ, Park H-S. Optimization of co-digestion of various industrial sludges for biogas production and sludge treatment: Methane production potential experiments and modeling. Waste Manage. 2014;34:1018-1024.

29. Wang X, Yang G, Li F, Feng Y, Ren G, Han X. Evaluation of two statistical methods for optimizing the feeding composition in anaerobic co-digestion: Mixture design and central composition design. Bioresour. Technol. 2013;131:172-178.

30. Liu C, Li H, Zhang Y, Liu C. Improve biogas production from low-organic-content sludge through high-solids anaerobic co-digestion with food waste. Bioresour. Technol. 2016;219: 252-260.

31. Owen WF, Stuckey DC, Healy JB, Young LY McCarty PL. Bioassay for monitoring biochemical methane potential and anaerobic toxicity. Water Res. 1979;13:485-492.

32. APHA, AWWA, WEF. Standard methods for the examination of water and wastewater. 22nd ed. Washington D.C.: American Public Health Association, American Water Works Association, Water Environment Federation; 1998.

33. Barker HA, Buswell AM. Biological formation of methane. J. Ind. Eng. Chem. 1956;48:1438-1443.

34. Park SH. Study of sludge pretreatment using microwave irradiation and ultrasonic. [dissertation]. Pusan: Dong-A Univ.; 2005.

35. Callaghan FJ, Wase DAJ, Thayanithy K, Forster CF. Continuous co-digestion of cattle slurry with fruit and vegetable wastes and chicken manure. Biomass Bioenerg. 2002;22:71-77.

36. Ma C, Liu J, Ye M, Zou L, Qian G, Li Y-Y. Towards utmost bioenergy conversion efficiency of food waste: Pretreatment, co-digestion, and reactor type. Renew. Sust. Energ. Rev. 2018;90:700-709. 